\title{
Impact of Management Support for Team Performance: A Sri Lankan Case study in Apparel Industry
}

\author{
Y.D. Pathirage, L.N.A.C. Jayawardena ${ }^{1 *}$ and T.N. Rajapaksha \\ Postgraduate Institute of Agriculture \\ University of Peradeniya \\ Sri Lanka
}

\begin{abstract}
A Study was conducted in a leading apparel manufacturing plant in Kandy district, Sri Lanka. The specific objectives of the study were to identify the dimensions of management support, to examine the level of team performance in the organization, and to analyze the impact of management support on team performance. A questionnaire was developed based on empirical models, and was administered for a sample of 114 employees. The sample was drawn by using stratified random sampling. Key informant discussions and focus group discussions were conducted to gain further insight into the findings. Descriptive and inferential (correlation, regression tests etc.) statistical analysis were done by using the SPSS software. Management support had six dimensions namely; defining key performance indicators, vision statement, decision making, problem solving, human resources \& administration service, and training \& development. Problem solving had the highest impact on team performance. Organization had a 'suggestions culture', which was promoted through management support. Employees perceived a high level of management support. Teams have recorded desirable levels of performance. Respondents were of the view that management support had increased team performance, which was reflected through a significant relationship in the correlation analysis. Creating successful work teams through optimal management support would add vitality to the performances.
\end{abstract}

Key words: Management support, team performance, effectiveness, decision making

\section{INTRODUCTION}

Production and manufacturing management has absorbed new concepts in rapid succession viz. manufacturing strategy, focused factory, just-in-time manufacturing, concurrent engineering, total quality management, supply chain management, flexible manufacturing systems, lean production, and mass customization, to name a few (Nesan and Holt, 2002). Sri Lanka's economic growth rate and gross domestic product (GDP) grew at an estimated $5.7 \%$ in 2010. A large proportion of the contribution to GDP comes from Sri Lankan private sector organizations. Textiles and apparel manufacturing industry is the country's largest foreign exchange earner, accounting for $46 \%$ of export earnings. It employs over 200,000 people directly and about another 400,000 indirectly, of nearly 750 factories in the industry (Central Bank, 2010). 'Human factor' is a major issue when optimizing manufacturing systems (Harrim and Alkshali, 2008). Apparel manufacturing industry in Sri Lanka has witnessed many challenges and demands, and increased competition. Maintaining a

Department of Agricultural Extension, Faculty of Agriculture University of Peradeniya, Peradeniya, Sri Lanka

Author for correspondence: chandanacj@yahoo.com 
motivated workforce and getting them involved in effective performance of organizations is vital. The importance and value of this study stems from several reasons. Industrial societies are meeting new challenges. Hence, the impact of management support for team performance in an apparel manufacturing organization is a key factor. Manufacturing firms are relying more and more on team based structures and designs. Empirical findings on management support and the effect on team and organizational effectiveness are limited in the Sri Lankan apparel manufacturing industry.

The multiple dimensions of management support and the impact on team performance lead to the following research problem. What is the impact of management support in Sri Lankan private sector organizations, especially in the apparel manufacturing industry? This paper focuses on the impact of management support as a mean enhancing performance. The study was carried out in an apparel manufacturing plant in Kandy, belonging to a well established exporter of apparels in Sri Lanka. Study has focused on the importance of management support and its impact on team performance. Findings of study provide empirical data for team leaders, top management, and team members for effective team performance. Overall objective of the study was to examine the dimensions of management support, and to assess the contribution to team performance in an apparel manufacturing plant in Sri Lanka. The specific objectives of the study were to identify the dimensions of management support, to examine the level of team performance in the organization, and to analyze the impact of management support on team performance.

McDonough et al (2003) suggested a model to achieve successful teams, with four factors $v i z$. setting the stage for product development by developing appropriate project goals, empowering the team with decision-making power, assigning appropriate human resources, and creating a productive climate to foster team success. Specific team behaviors, including cooperation, commitment to the project, ownership of the project, and respect and trust among team members have been posited to contribute to team success. Researchers suggest that team leaders, senior managers, and champions support teams in achieving success. Team leadership is the most frequently mentioned enabler, followed by management support. In supporting teams, the supervisor's role to bring out the potential in employees has been mentioned in studies. The process is best described as mentoring or coaching (Karen, 1997). Psoinos and Smithson (2002) suggest determining the skill level of the employee, sharing information about the goals to be achieved and its importance to the organization, and providing for employee training have to be followed by providing appropriate supervisory support based on employee skill level. A directive style when the employee has a low skill level, coaching for the tasks employee is having some skills but lacking experience or motivation, supportive style for the tasks employee knows what to do but is lacking confidence in his abilities, and delegation when the employee is motivated and capable. Ensuring the employee is consistently growing in skill by providing new responsibilities and a higher level of supervision, and mentoring him to absorb organizational culture and the value of empowerment are vital. Liker (2003) in "The Toyota Way" has elaborated how the manufacturing unit has been designed on value adding teams. And it consists of a group leader responsible for product quality, monitoring yield, quality systems management, and environmental sustainment. Team Leader is responsible for the results, which eventually are the factory goals. Team members do the organizational value addition.

Management's involvement is indispensable for effective implementation of strategy. 'Top management provides a role model for other managers in assessing the salient environmental variables, their relationship to the organization, and the appropriateness of the organization's response to these variables. Top management shapes the perceived relationships among 
organization components. Management is largely responsible for the determination of organization structure (e.g., information flow, decision-making processes, and job assignments). They must recognize the existing organization culture and learn to work within or change its parameters. Management is also responsible for the design and control of the organization's reward and incentive systems' (Kzatz \& Thomas, 2011). Management is involved in the design of information systems for the organization. In this role, managers influence the key environmental variables to the organization. They must be certain that information concerning these key variables is available to the managers. Top-level managers must also provide accurate and timely feedback concerning the organization's performance and the performance of strategic business units of the organization. Considerable research on practices such as gain-sharing, communication programs, work teams, job enrichment, skillbased pay, and so on has shown the results of these practices to be consistent and positive. When there is support from management, worker satisfaction and quality of work life has improved. Qualities of goods and services and productivity have reportedly improved as a result of employee involvement efforts in about two-thirds of the companies. Internal stakeholders need information to maintain a realistic view of their performance, performance of the organization, and the organization's relationship to the environment (Kzatz \& Thomas, 2011). Gemuneden and Lechler (1997) have defined team performance as the extent to which a team is capable to meet the established quality, cost and time objectives. They indicated that the perception of project's success depends, in part, on the perspective of the measures evaluated, such as, effectiveness, efficiency, learning, work satisfaction, team conflict, effort, balance of member contribution, mutual support, cohesion, coordination and cooperation. 


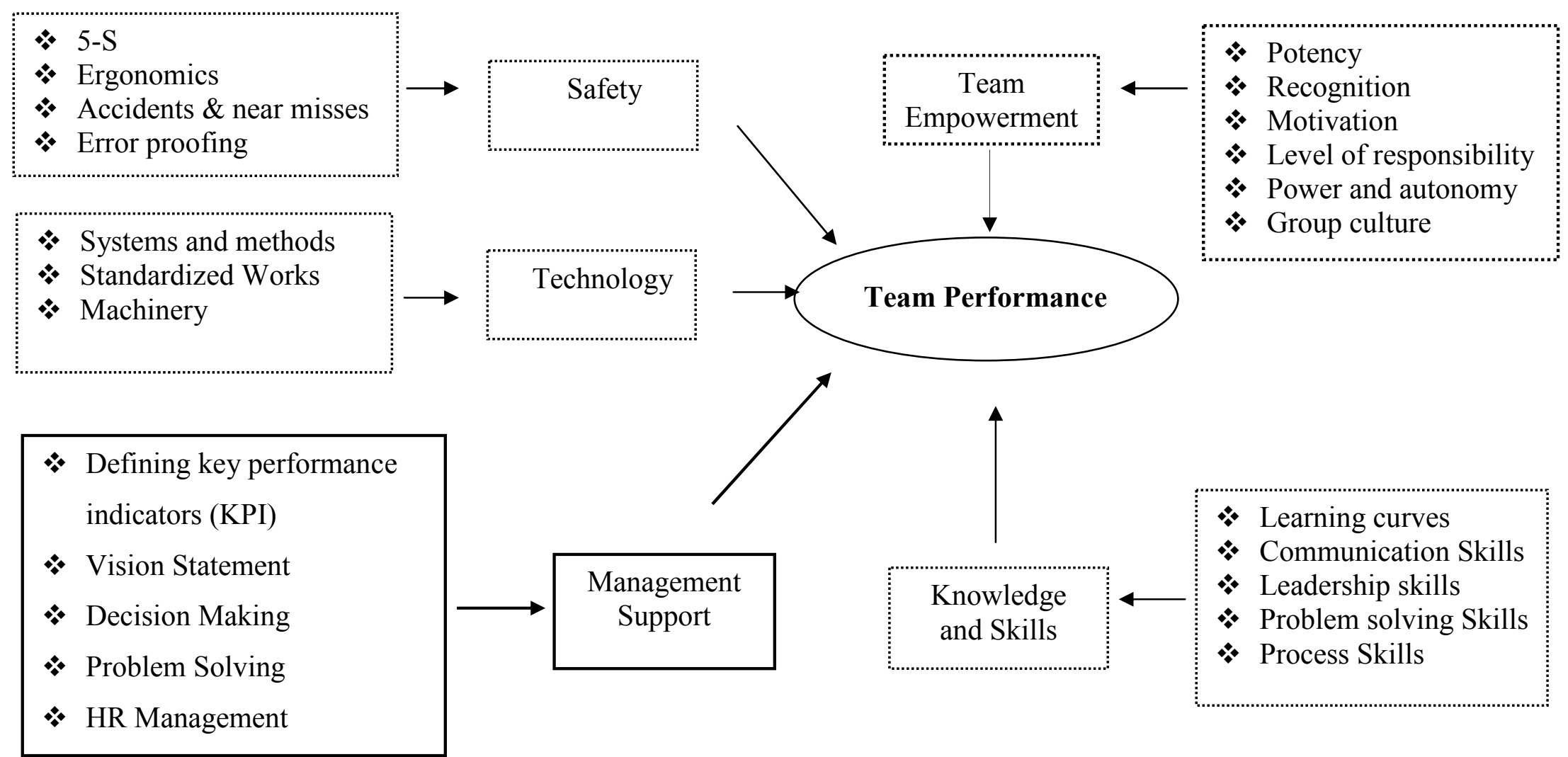

Fig. 1. Conceptual Framework

Source: Developed by integrating and modifying the models of Schwartz (1994), Vosburgh (2007), Martin and Hans, (2001) and Kirkman (1999). 


\section{MATERIALS AND METHOD}

A manufacturing plant, based in Kandy district, belonging to a leading apparel export organization in Sri Lanka was selected as the sample frame. Team Members (TM), Team Leaders (TL), Group Leaders (GL), Production Managers (PM) and Value Stream Manager (VSM) (Fig. 2) constituted the sample frame. Sample size of 114, was drawn by using stratified random sampling.

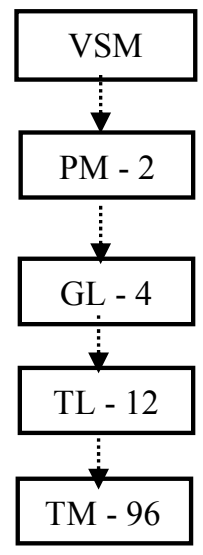

Fig. 2. Stratified random sampling framework

The questionnaire was prepared to capture the data for the major variables of the study focused on the objectives. It was structured to facilitate the obtaining of in-depth information and was modified through pretesting to facilitate clarity. Primary data were obtained from all levels of employees in the sample. A key informant discussion (KID) was conducted to enrich the findings. Secondary data were collected from organizational performance reports, publications, and research reports. Management Support was the main independent variable. Defining KPIs, Vision Statement, Quick Decision Making, Problem Solving, HR \& Administration service, Training \& Development were the sub variables. Team performance was the dependant variable. The hypothesis constructed for the study was as follows:

Ho - Management support (the dimensions viz: Defining KPIs, Vision Statement, Decision Making, Problem Solving, HR and Administration service, Training and development) has no significant effect on Tea m Performance.

Data were collected through questionnaire and interview schedule. A survey KID and focus group discussions were employed. Respondents were briefed in the survey and filled questionnaires on their own. Coding and data entry were done using the SPSS computer software. Analysis involved frequency distributions to describe demographic data of respondents, descriptive statistics of mean and standard deviation to calculate central tendency and dispersion (variance) of responses of respondents to the specific questions, coefficient to ensure internal reliability of questionnaire, ANOVA analysis and linear regression analysis to test the six specific hypotheses on the effect of dimensions of management support on team performance. 


\section{RESULTS AND DISCUSSION}

The largest proportion of respondents (TLs and TMs) had obtained senior secondary education (A/L) education. More than $96 \%$ of the respondents had been successful at GCE (Ordinary) level. The relatively high education level of respondents (employees) would have facilitated the transfer of knowledge and skills, and understanding of various aspects related to work and the work environment at all levels. About $72 \%$ of TLs earned more than Rs 14,000 per month, and $50 \%$ of them earned over Rs 17,000 per month. About $60 \%$ of TMs earned Rs 8,000 - 10,000 per month, and $23 \%$ of them earned over Rs 13,000 per month. Table 1 displays the mean (M), and standard deviation (SD) of the three main variables viz; Team empowerment, management support, and team performance of respondents. The $\mathrm{M}$ and SD values for management support $(4.21,0.83$ respectively) suggest that respondents had perceived a relatively high level of management support. Among the six subscales of management support, problem solving scored the highest mean value of 5.25 (SD of 0.96), indicating that employees were highly satisfied of their problem solving culture and the management support for the same. Organization had given a high importance to problem solving. Once the problem was created there was an ANDON system to surface the problem quickly to the supportive departments. Organizational reports recorded an average response time of 5 min to solve problems. If the same problem resurfaced within 3 days, supportive departments and operational teams had to find the root cause through the problem solving techniques. There was a dedicated problem solving meeting room, facilitators, and recorders. There was a 30 min compulsory meeting every week to discuss work problems. Production flow was structured to the modular concept with 16 team members. Each member was designated to a specific job role. Everybody was personally accountable for team's success. Management promoted 'group culture' through rewards based on team performance. Table 1 depicts a mean value 4.19 for team performance with a SD of 0.79 . This indicates a higher level of team performance. The SD values indicated that majority of the observations were similar.

Table 1. Factors related for team performance

\begin{tabular}{llcccc}
\hline Variables & Items & Alpha & Mean & $\begin{array}{c}\text { Standard } \\
\text { deviation }\end{array}$ \\
\hline \multirow{3}{*}{ Management } & Defining KPIs & 4 & 0.78 & 4.12 & 0.87 \\
support & Vision statement & 5 & 0.62 & 3.86 & 0.79 \\
& Problem solving & 4 & 0.91 & 5.25 & 0.96 \\
& Decision making & 5 & 0.86 & 4.63 & 0.86 \\
Team performance & HR Management & 6 & 0.87 & 4.31 & 0.79 \\
& Training and development & 6 & 0.82 & 3.99 & 0.73 \\
& All subscales (overall) & $\mathbf{3 0}$ & $\mathbf{0 . 8 4}$ & $\mathbf{4 . 2 1}$ & $\mathbf{0 . 8 3}$ \\
& & $\mathbf{4 0}$ & $\mathbf{0 . 8 6}$ & $\mathbf{4 . 1 9}$ & $\mathbf{0 . 7 9}$ \\
\hline
\end{tabular}

Correlations and regression analysis were employed to estimate the causal relationships between management support and team performance. Pearson's correlation coefficient analysis was used to assess the relationships of variables between management support and team performance. Performance had a positive relationship with Management support. Table 2 depicts a significant positive relationship between management support and team performance, with the correlation coefficient at 0.78 . It was highly significant at $\dot{\alpha}=1 \%$, indicating that management support had been related to improved team performances. 
Table 2. Relationship between management support and team performance

\begin{tabular}{lll}
\hline Variables & & Team performance \\
\hline Team performance & Pearson Correlation & 1 \\
& Sig. (1-tailed) & \\
Management support & Pearson Correlation & $0.78($ at $\alpha=1 \%)$ \\
& Sig. (1-tailed) & 0.00 \\
& Number of respondents & 114 \\
Six-point scale: $\mathbf{6}=$ Strongly agree to $\mathbf{1}=$ Strongly disagree. & \\
\hline
\end{tabular}

Regression analysis was used to identify the variables influencing team performance. Table 3 indicates that coefficients of management support were significant. It indicated a positive relationship between management support and team performance. Beta values for management support indicated contribution of management support for team performance. The value of $\left(R^{2}\right)$ for management support was $79.4 \%$ and the adjusted $R^{2}$ for the same was $73.5 \%$. This indicated that $73.5 \%$ of the variation in team performance is explained by management support. Larger values of $\mathrm{R}$ indicated stronger relationships. F-value showed that the overall model was statistically significant. Results assured that management support resulted in higher team performance.

Table 3. Regression Analysis- ANOVA/ T - Coefficients

\begin{tabular}{lcc}
\hline \multirow{2}{*}{ Statistical indicators } & \multicolumn{2}{c}{ Management support } \\
\cline { 2 - 3 } & Value & Significant probability level \\
\hline $\mathrm{F}$ & 51.73 & 0.00 \\
Beta coefficients & 0.871 & \\
$\mathrm{~T}$ & 17.594 & \\
$\mathrm{R}^{2}$ & 0.794 & \\
Adjusted $\mathrm{R}^{2}$ & 0.735 & \\
\hline
\end{tabular}

Ho: Management support has no significant effect on team performance.

Table 4 depicts that the sub variables of management support viz: reliable KPIs, vision statement, decision making, problem solving, HRM, training and development had significant impact on team performance at $(\mathrm{p} \leq 0.05$. The highest being problem solving $(\mathrm{B}=$ $0.73)$, and the lowest was vision statement $(B=0.31)$. Management's belief in the importance of vision to drive the business was verified in KPIs. Majority (76\%) of the respondents lacked sufficient understanding of the linkage between their work and company vision. They were only concerned of their routine work assignments. The coefficient of determination $\left(\mathrm{R}^{2}\right)$ for management support suggested that $48 \%$ of the variation in team performance was explained by variation in management support. The calculated $\mathrm{F}$ value was 43.01 at $(p \leq 0.05)$, and the hypothesis could not be rejected. It can be concluded that management support had a significant effect on team performance. Results indicated that team performance was significantly related to management support of the organization. 
Table 4. Regression analysis- impact of management support to team performance

\begin{tabular}{lccc}
\hline $\begin{array}{l}\text { Management support } \\
\text { dimensions }\end{array}$ & B & T & $\begin{array}{c}\text { Significant } \\
\text { probability level }\end{array}$ \\
\hline Defining KPI"s & 0.41 & 4.78 & 0.05 \\
Vision statement & 0.31 & 3.69 & 0.00 \\
Decision making & 0.57 & 6.11 & 0.00 \\
Problem solving & 0.73 & 8.43 & 0.00 \\
HR management & 0.59 & 6.79 & 0.00 \\
Training and development & 0.64 & 7.21 & 0.00 \\
$\mathrm{R}^{2}=0.48$ & $\mathrm{~F}=43.01$ & & Sig. $=0.00$ \\
\hline
\end{tabular}

Top management was largely responsible for the determination of organizational structure $v i z$ information flow, decision-making processes, and job assignments etc. Organization had preferred experienced TMs at recruitment. About $64 \%$ of TMs had been recruited with some experience in apparel industry. Organization had provided training to TMs and TLs to enhance their decision making skills. They were computer training, lean manufacturing, 6-S, machine and technical training, defects identification, and problem solving techniques. The knowledge and skills gained from the training were intended to facilitate autonomous decision making without always depending on the supervisor. Establishing advisory services, counseling, and library facilities were aimed at enhancing the personal and group capacities of employees. There was a project focused at non-executive level female employees to enhance their personal lifestyles. Organization also encouraged a 'first name culture' among employees, which is not the norm in Sri Lankan/ Asian culture. However, there was a marked difference in the status-quo between SOs, supervisors, and rest of the staff. Organization had a 'suggestions culture', wherein management support was provided to implement the better suggestions and to reward employees. They had two main meetings viz. the cross functional meeting to solve operational level problems with the attendance of supporting departments, and the management meeting to make strategic decisions.

\section{CONCLUSIONS}

This paper concludes that management support significantly increases the team performance. The research has established that team performance has a positive relationship with management support. The beta coefficient of management support was 0.87 . The overall model was found significant. Among the six sub variables of management support, employees were highly satisfied of their problem solving culture and the management support provided for the same. The results of this study would be useful for team leaders and managers to understand the importance of management support for team performance. Findings also suggest that team performance captures many dimensions of performance factors. These are elements of social behavior in terms of activities, interactions and sentiments. Activities are directly observed through outputs, interactions are related to "being in contact", and sentiments are reflected through motivations and emotions. Though this research was limited to a single plant (large scale) of an established apparel manufacturing plant, above findings will be helpful in trying to create successful work teams through optimal management support. 


\section{REFERENCES}

Central Bank (2010). Annual Report 2010. Central Bank of Sri Lanka, Colombo.

Gemuenden, H.G. and Lechler, T (1997), Success Factors of Project Management: The Critical Few: An Empirical Investigation, Portland International Conference on Management of Engineering and Technology, 1997, pp. $375-377$

Harrim, H.M. and Alkshali, S.J (2008) Employees' Empowerment and Its Effect on Team effectiveness: Field Study on Jordanian Construction Firms. Jordan J. Business Administration, 2008, Vol. 4, (01), 107-121.

Karen, A. J. (1997). Multi Method Examination of the Benefits and Detriments of Intra Group Conflict, Administrative Science Quarterly. 40 (02), 256 - 282

Kirkman, B. L, and Rosen, B. (1999).Beyond self-management: Antecedents and consequences of team empowerment. Academy of Management Journal. 42. 58-74.

Kzatz, D.A. and Thomas J.G. (2011), Strategic Planning Failure. Available at $<$ http://www.referenceforbusiness.com/management $>$ [accessed $20^{\text {th }}$ August, 2011]

Liker, J. K . (2003). The Toyota Way, $1^{\text {st }}$ ed., McGraw-Hill, New York.

Martin, H. and Hans, G.G. (2001).Team work quality and success of innovative projects. A Theoretical Concept and Empirical Organization Science. 12 (04), 435-449.

McDonough III, E.F. Kahn, K B. and Barczak, G. (2003), An investigation of the use of global, virtual, and collocated new product development teams, Journal of Product Innovation Management, [online]. <http://onlinelibrary.wiley.com/doi/10.1111/1540$5885.1820110 / \mathrm{pdf}>$ [accessed $15^{\text {th }}$ August, 2011]

Nesan, L. J. and Holt, G.D. (2002). Assessment of Organizational Involvement in Implementing Empowerment, Integrated Manufacturing Systems, 13 (04), 201-211

Psoinos, A. and Smithson, S. (2002). Employee Empowerment in Manufacturing: A Study of Organizations in UK. New Technology, Work and Employment, 17 (02), 132 - 148

Schwartz, S.H. (1994). Beyond individualism/collectivism: New dimensions of values. Individualism and Collectivism: Theory Application and Methods. Kim, U. Triandis, H.C. Kagitcibasi, C. Choi S.C. and Yoon, G. Newbury Park, California, Sage, 1994.

Vosburgh, R.M. (2007) The Evolution of HR: Developing HR as an Internal Consulting Organization. Human Resource Planning, 30 (03), 11-12 